\title{
Una breve incursión por el Carnaval de Isla Cristina, una celebración centenaria
}

Agustín P. Figuereo | historiador

URL de la contribución <www.iaph.es/revistaph/index.php/revistaph/issue/view/4348>

\section{RESUMEN}

El Carnaval de Isla Cristina, declarado de Interés Turístico de Andalucía, es la fiesta por antonomasia de la localidad. Celebrada desde el propio origen de la población a mediados del siglo dieciocho, ha ido creciendo a lo largo del tiempo, tanto en duración como en componentes que lo hacen único frente a otros de la zona y conjugando un período especial donde el pueblo se manifiesta tal cual, siendo capaz de enfrentarse abiertamente al poder establecido y demostrando su fuerza.

\section{Palabras claves}

Carnaval | Comparsas | Concurso de agrupaciones | Coros | Fiesta | Isla Cristina (Huelva) | Murgas | 


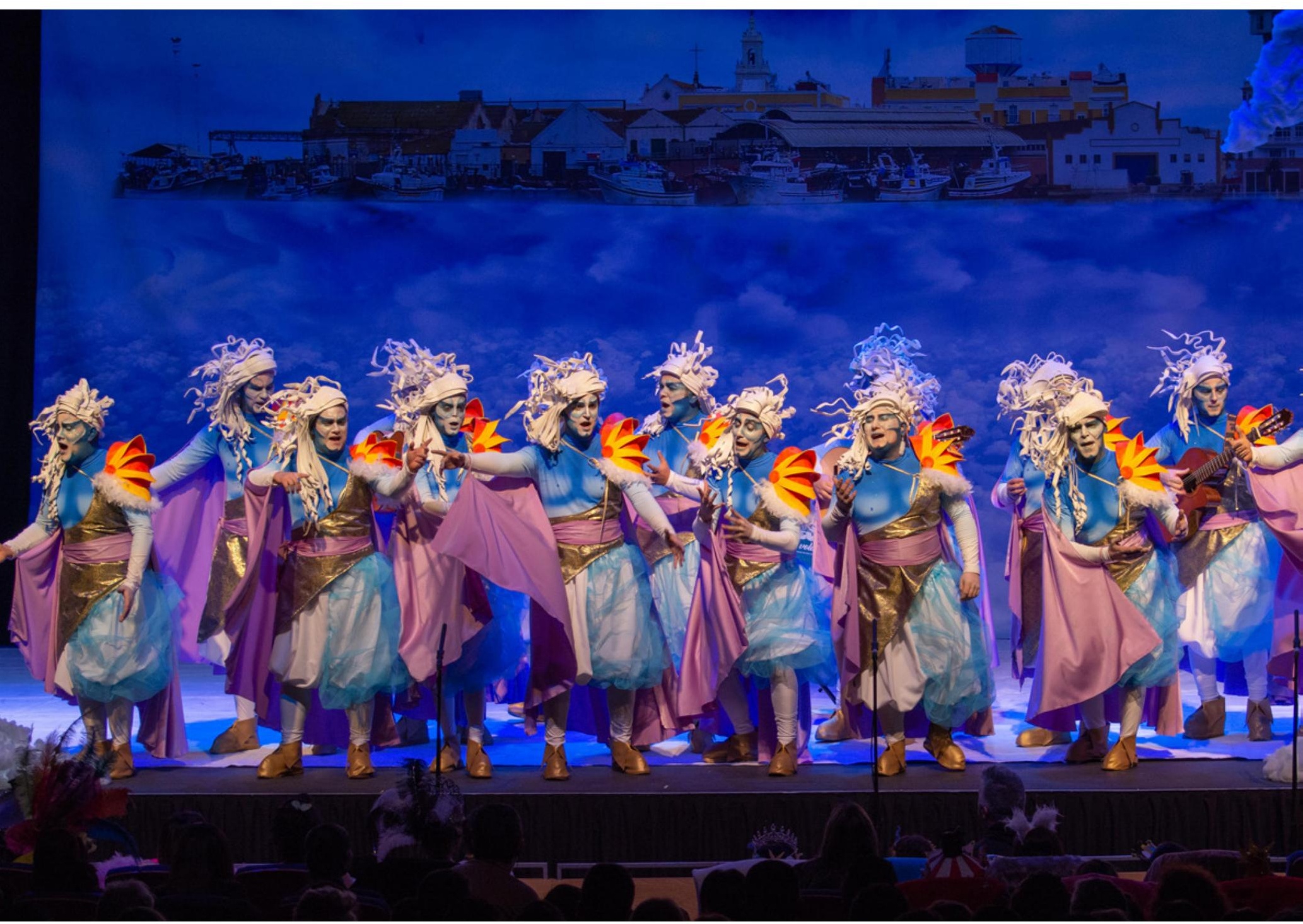

Actuación de una comparsa en el Teatro Municipal "Horacio Noguera" | foto Joaquín Cristóbal, autor de todas las imágenes que ilustran este artículo 
1

Archivo Municipal de Isla Cristina (en adelante, AMIC), Leg. 46, Bando con las normas para la salvaguarda del orden y la moral en la ciudad, 1832

2

AMIC, Leg. 46, Bando, 1858
El Carnaval de Isla Cristina es, sin duda, la fiesta más auténtica y genuina de todas las que se celebran en la localidad.

Tiene su origen, probablemente, en el siglo XVIII, cuando se configura el actual núcleo urbano a raíz del terremoto-maremoto llamado de Lisboa, ocurrido el 1 de noviembre de 1755 . Desde fechas muy tempranas hay constancia de algún tipo de celebración en torno a las fechas de Carnaval, históricamente los tres días anteriores al Miércoles de Ceniza, donde los Ilamados "traficantes de salados" de procedencia catalana y levantina daban por finalizada la temporada en nuestra tierra y emprendían el retorno a sus lugares de origen para volver, de nuevo, en torno a la festividad de San Pedro a finales del mes de junio.

Una vez que la población fue asentándose y consolidándose en el territorio, el Carnaval fue desarrollándose, apareciendo las primeras referencias escritas, de manera transversal, en torno al año 1832, cuando el regidor Lorenzo Elías dicta unas "prevenciones" para proteger la moralidad de los habitantes de la Real Isla. Dos de ellas afectan directamente a nuestra fiesta:

" $33^{a}$. No se prohíben las mascaras y diversiones racionales en los tres días de Carnestolendas autorizadas por el tiempo y la costumbre.

$34^{a}$. No se consideran contenidas en la prevención $33^{a}$ la multitud de prácticas abusivas que ni tienden al placer ni desahogo público ni guarden conformidad con la seguridad personal, el decoro popular, la decencia ni las buenas costumbres"1.

Otro bando, esta vez de 1858, recoge la prohibición de vestir con trajes de ministros de la religión, militares o institucionales, llevar armas o verter aguas fecales sobre los enmascarados. A su vez, se permitía una mayor apertura de los establecimientos de juego y de bebidas, que permanecerían abiertos "hasta el toque de ánimas"2.

En esos años se produce un cambio sustancial en las fiestas, ampliándose su celebración al fin de semana anterior al miércoles de ceniza, además de los tres días ya consabidos, y aunque en 1867 hay un intento de volver a los días concretos, no fue posible conseguirlo por parte de la autoridad.

Isla Cristina, que contaba con un teatro estable al menos desde 1868, incorpora este elemento a su Carnaval a partir de entonces. Desde aquel primitivo teatro, cuyo nombre se desconoce, pero que estaba establecido en la calle San Salvador, hoy denominada Diego Pérez Milá, pasando por el Teatro Flores (levantado por Juan Flores Amo en terrenos de su propiedad en la llamada por él calle Flores) o, ya avanzado el siglo XX, por el Salón Circo 
Victoria, el Gran Vía, el Cine Victoria, el Palacio del Carnaval y, desde principios del siglo XXI, el Teatro Municipal "Horacio Noguera", los diferentes coliseos han jugado un importantísimo papel en las fiestas, primero como lugar de celebración de bailes públicos y luego como sede de un genuino concurso de agrupaciones musicales.

Las ordenanzas municipales de $1876^{3}$ ya recogen formalmente al Carnaval dentro del epígrafe de "Festividades populares", dedicándole doce artícu-
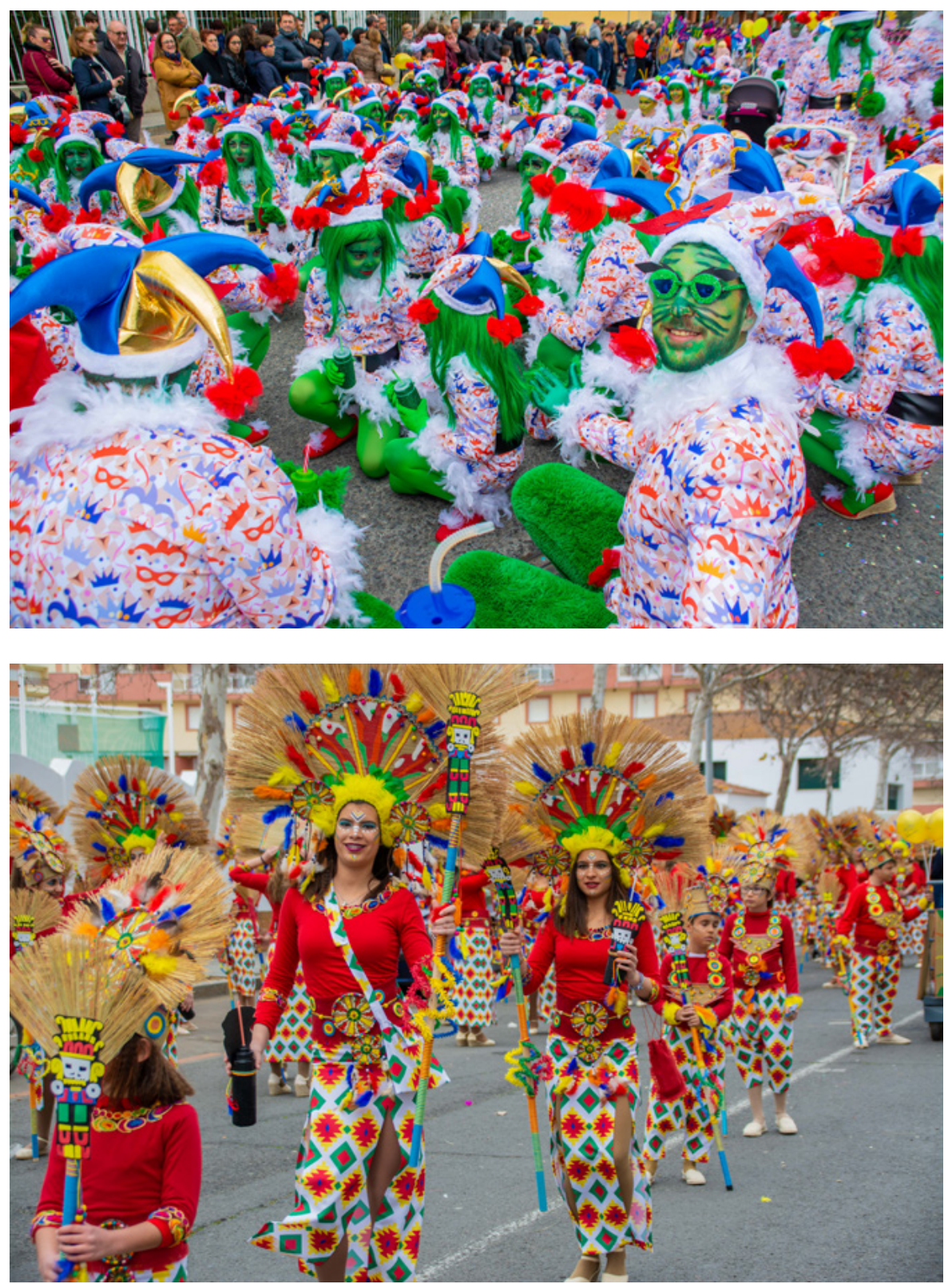

3

AMIC, Leg. 93, Ordenanzas Municipales, 1876.

Grupo de disfraces en la Gran cabalgata 


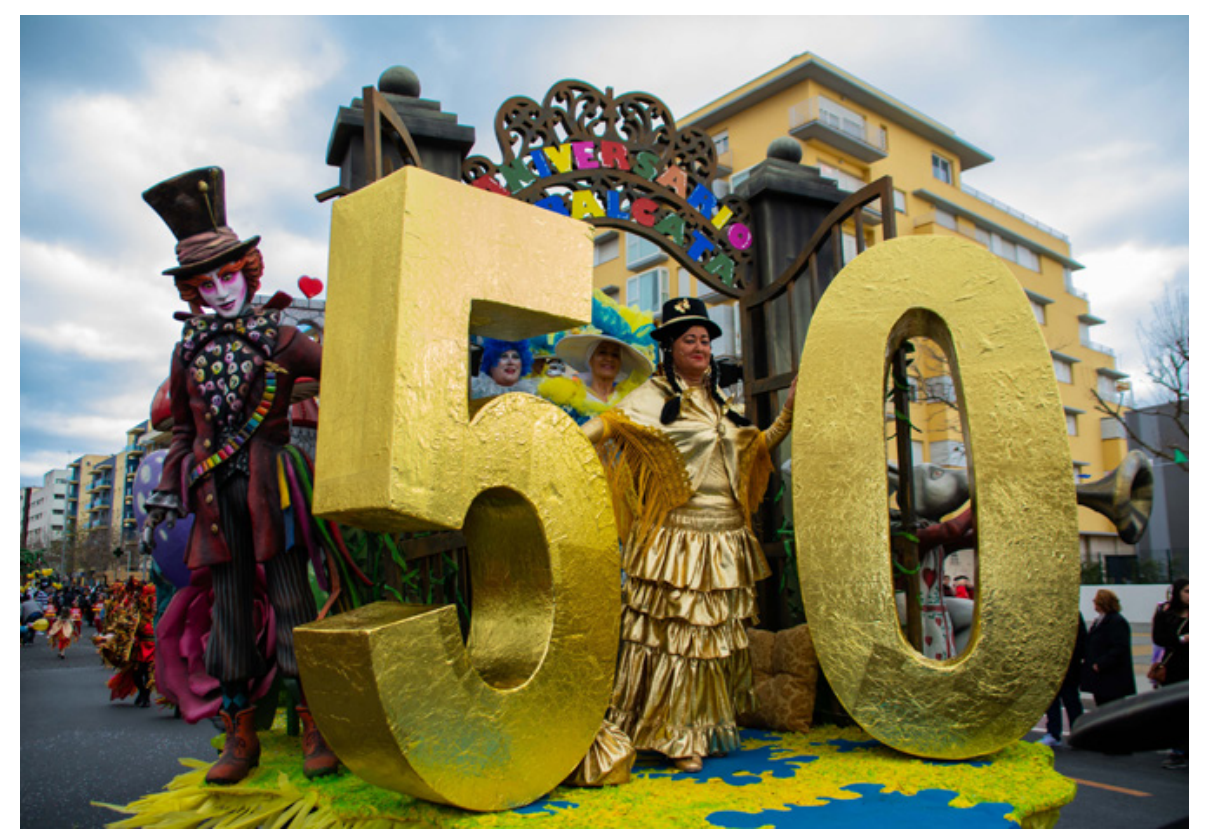

los, donde además de insistir en lo expuesto en bandos anteriores en relación con la prohibición de disfrazarse de miembros del ejército o del clero, de portar armas "o espuelas", arrogaban a la autoridad municipal competente el derecho a desenmascarar a aquellos que cometieran alguna falta, a presidir las funciones del teatro, al comportamiento del público en el mismo $y$, por primera vez, fijaban unas multas que oscilaban entre cinco y diez pesetas.

Contamos ya con el esquema básico por el que será conocido el Carnaval de Isla Cristina: por un lado, la importancia de la calle, de la diversión espontánea de la gente disfrazada dando paseos, gastando bromas y divirtiéndose sanamente, culminando todo ello en el día más importante del Carnaval, el Miércoles de Ceniza, día en el que se celebra el Entierro de la Sardina como verdadero fin de fiestas; de otro, con la aparición del teatro, nacen los bailes de sociedad y también entra en escena el elemento musical.

La influencia que recibe el Carnaval de Isla Cristina es triple, actuando como verdadero lugar donde se produce un choque de culturas: los primitivos fundadores, provenientes del noreste peninsular traen sus celebraciones $y$, casi con total seguridad, aportan el Entierro de la sardina; Cádiz está presente, como capital marítima de la cual dependió la Real Isla de la Higuerita (antigua denominación de Isla Cristina) durante muchísimos años, en la forma de entender las agrupaciones musicales; por último, la cercanía de Portugal, de donde no solo llegaron muchísimos trabajadores sino también la idea de los desfiles, los disfraces más elaborados, etc. 


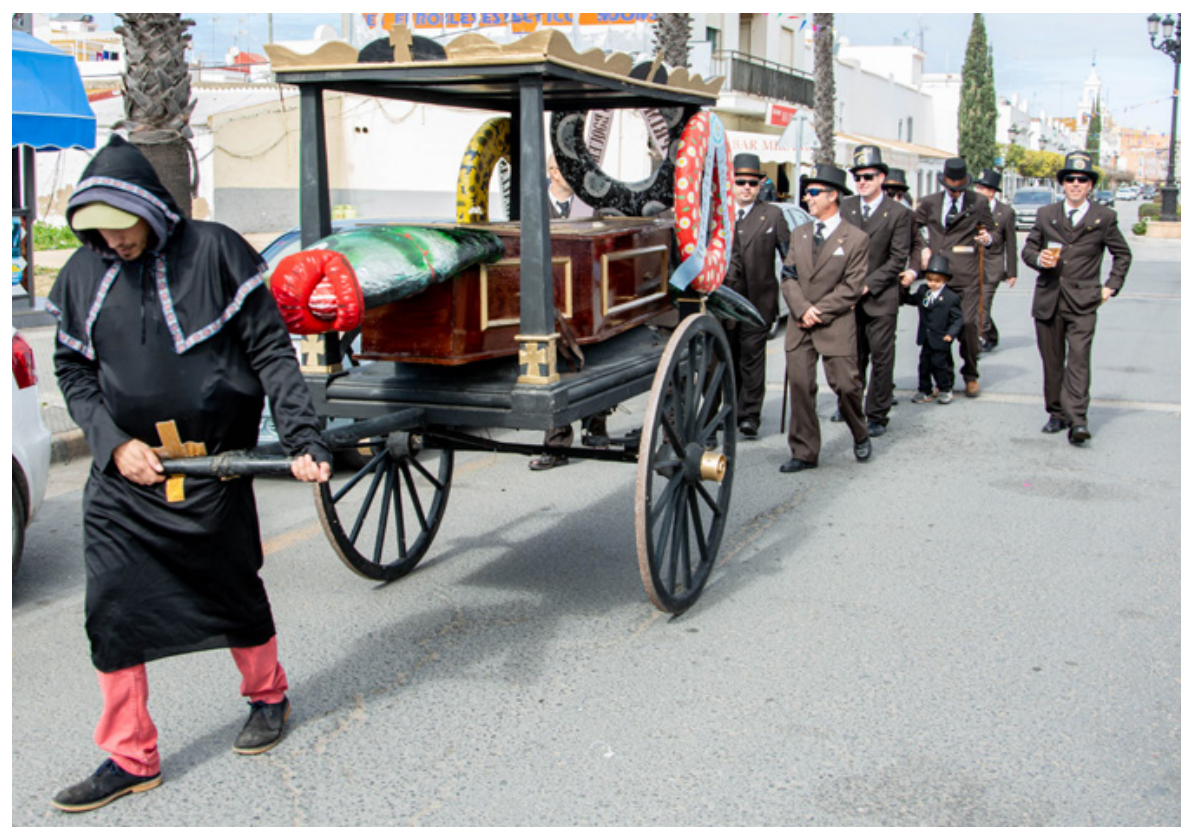

Cortejo fúnebre previo al Entierro de la sardina

Al hilo de la influencia gaditana, por ejemplo, cabe destacar la visita realizada a nuestra ciudad por el mítico coro Los Anticuarios, en la temprana fecha de 1906, en una gira como las que hoy en día se realizan, y que dejó flotando en el aire los sones de aquel mítico tanguillo de "Los duros antiguos". No obstante, la primera letra de carnaval documentada en Isla Cristina se fecha aproximadamente hacia 1880-1881.

Tres modalidades musicales se convertirían en las básicas durante el primer tercio del siglo XX, el coro, la comparsa y la murga. El coro lo conformaban alrededor de cuarenta componentes, acompañados de multitud de instrumentos musicales: violines, guitarras, laúdes, flautas, saxofones, etc.; la comparsa, formada por un número bastante inferior de miembros, llevaban, como hoy, guitarras, bombos y pitos, siendo su repertorio más serio; por último, las murgas aportaban la parte más cómica y grotesca, con letras humorísticas y donde no solía haber instrumentos de cuerda, únicamente bombos, cajas y pitos de caña.

Del año 1919 data una histórica fotografía que recoge dos hechos fundamentales del Carnaval de Isla Cristina, documentando, de una parte, a una comparsa, "Las Regiones Españolas", siendo la primera imagen que tenemos de una agrupación, pero, de otra parte, nos la muestra en una actuación en plena calle, en algo así como la primera carroza que podemos fechar, con la importancia que para la fiesta tiene hoy en día la Gran cabalgata. En dicha imagen los miembros de la comparsa están sobre un carro decorado con los mismos escudos que lucía la agrupación, siendo el carro tirado por un mulo. 


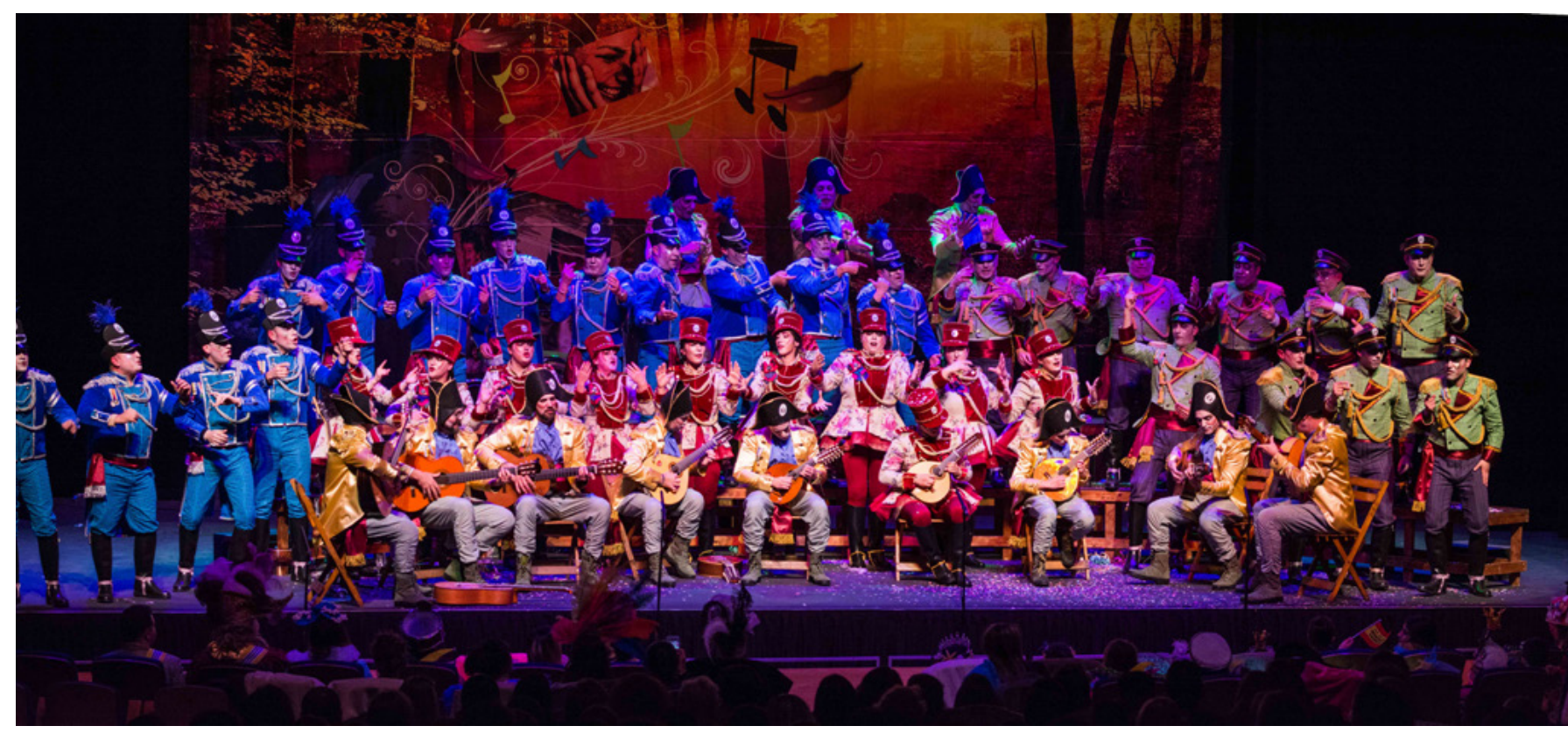

Actuación de un coro en el Teatro Municipal "Horacio Noguera" | foto Joaquín Cristóbal

A partir de entonces nacerán los reñidos concursos entre agrupaciones, a la vez que continuaba celebrándose la calle, ahora alargándose hasta el domingo posterior al Miércoles de Ceniza con la tradicional rotura de piñatas, y los bailes celebrados en teatros, casinos y sociedades de recreo.

La Guerra Civil de 1936 acabaría con todo esto, siendo muchos de los autores y directores más destacados del carnaval fusilados $u$ obligados a marchar al exilio.

Sin embargo, y pese a la prohibición oficial del Carnaval por parte de la dictadura, a partir de mediados de la década de 1940 se conservan los primeros testimonios gráficos de disfraces callejeros, convirtiéndose el salir a la calle en todo un desafío a la autoridad que, sin embargo, fue bastante permisiva.

Las carrozas empezarían a tomar las calles prácticamente una década después, mientras que el concurso de agrupaciones volvió a celebrarse a partir del año 1968 bajo el nombre de Fiestas Típicas de Invierno, siguiendo fiel a su fecha invernal, a diferencia de otras localidades.

El crecimiento del Carnaval, declarado Fiesta de Interés Turístico, ha ido a más, contando con una duración aproximada de tres semanas incluyendo todos sus formatos, desde el concurso de agrupaciones hasta el Domingo de Piñatas, con días que pasan por mayor predilección del público al socaire de las modas y los gustos porque, al final, el carnaval lo hace el pueblo y poco control tiene. 


\section{BIBLIOGRAFÍA}

- BIEDMA VISO, J. (2004) Carnavales de Isla Cristina. $2^{a}$ Ed. Isla Cristina: Ayuntamiento, 2004

- BIEDMA VISO, J. (1992) Carnavales de Isla Cristina (1982-1992). José Biedma Viso, 1992

- FiguereO, A. P. (2001) El Sexenio Revolucionario en Isla Cristina. Boletín de Estudios Históricos ELD, Asociación Cultural El Laúd, Isla Cristina, 2001

- LÓPEZ MÁRQUEZ, V. (2006) Isla Cristina. Por los caminos de la Historia. Huelva: Diputación Provincial, 2006

- SOSA RODRíGuEZ, J. (1970) Historia de Isla Cristina (Biografía sentimental). José Sosa Rodríguez, 1970 